\title{
EL COMBATE ENTRE EL MUNDO Y LA RAZÓN SEGÚN PEDRO COMPOSTELANO
}

\author{
César Raña Dafonte \\ Universidad de Santiago de Compostela
}

Pretendo, primordialmente, poner en claro los aspectos éticos que sin duda son muy relevantes en la obra De Consolatione Rationis. La finalidad esencial del autor es la presentación de un código moral que sirva de sustento y orientación al hombre en este mundo, en el que es un mero viator.

Dada la peculiar dificultad que presenta la identificación del autor, en especial lo referente a la ubicación cronológica, así como la problemática inherente a una obra de la que se conserva un solo ejemplar manuscrito en un latín no siempre fácil de interpretar, nos vemos obligados a realizar una presentación, aunque sea muy breve, de estos temas. La exposición constará, pues, de dos apartados:

1.- Presentación de la problemática en torno a la obra y a su autor. ${ }^{1}$

2.- Análisis de la dimensión ética de la obra.

\section{LA OBRA DE CONSOLATIONE RATIONIS: PROBLEMÁTICA}

Sólo se conserva un ejemplar manuscrito en latín, con letra gótica, en la biblioteca del Monasterio del Escorial. Forma parte de un Códice con la signatura R, II, 14. Nuestro escrito abarca desde el folio 33 vuelto al 53 recto. Comienza con el siguiente epígrafe: «Incipit prohemium Magistri Petri Compostellani de Consolatione Rationis in honorem Domini Archiepiscopi Compostellani». El nombre Petrus no vuelve a encontrarse en toda la obra. En lo sucesivo sólo aparece Compostellanus. La escritura pertenece al siglo XIV. Se alterna el verso y la prosa, y la forma es dialogada. Es más que probable que no se trate del escrito original que salió de manos del autor. Más bien da la impresión de ser una copia, y no de

1 Sobre este apartado ya hice una referencia en el número 0 de la Revista. Por alguna errata importante, reitero parte de lo dicho allí. 
un experto en latín precisamente (abundan las incorrecciones tanto sintácticas como morfológicas, las abreviaturas...). Es significativo que ni en Santiago de Compostela ni en otro lugar de Galicia se haya conservado (al menos que se sepa) ningún ejemplar de la obra, que se supone escrita en Santiago.

Hasta el momento sólo se ha hecho una transcripción al latín normalizado, realizada por Pedro Blanco Soto. No ha sido traducida a otro idioma. ${ }^{2}$ La transcripción tiene el gran mérito de ser la única hasta el momento, con la enorme dificultad que implicó tal realización. Pero adolece de multitud de carencias. Ello nos indica la perentoria necesidad de una nueva transcripción, así como una traducción al castellano con garantías.

\section{Trabajos realizados hasta el momento sobre la obra}

Señalando tan sólo los trabajos más significativos, hemos de recordar, ante todo, al primero que se ocupó de la Consolación de la Razón: José Pérez Báyer. Tanto en el Catálogo de la Biblioteca del Escorial (1765), como en la edición que realiza de la Bibliotheca Hispana Vetus de Nicolás Antonio (1788), hace hincapié en el interés que, a su juicio, merece la obra del Compostelano (la data en el siglo XIV).

Ha de reseñarse también el estudio de José Amador de los Ríos, en su Historia Crítica de la Literatura Española, Madrid, $1862^{3}$ (la data en el siglo XII).

El más importante trabajo que sobre nuestra obra se realizó hasta el momento es el de Pedro Blanco Soto, que, como hemos dicho, por primera vez hizo una transcripción al latín actual, con las enormes dificultades que ello supone. Además antepone a la transcripción un amplio estudio introductorio (en alemán y castellano). (Data también la obra del Compostelano en el siglo XII). ${ }^{4}$

Para las investigaciones más actuales sobre nuestro autor, merecen una mención especial dos interesantes trabajos. El primero es de Casimiro Torres Rodríguez titulado $E l$ maestro Pedro Compostelano. Un Compostelano olvidado 5 . En él se analiza el Códice que contiene nuestra obra, se señalan los principales estudios, el argumento, así como el problema de la datación de la obra. Sobresale, asimismo, el cotejo que hace entre Pedro Compostelano y Alano de Lille ( $\uparrow 1203)$. El segundo trabajo es el realizado por María González-Haba: La obra de De Consolatione Rationis de Petrus Compostellanus ${ }^{6}$. En su

2 Sólo hemos visto un intento de traducción al castellano. Se trata de una Memoria de Licenciatura presentada en la Universidad de Valencia en el año 1972, por Jesús Tobío Fernández: La obra De Consolatione - Rationis de Pedro Compostelano. Un testimonio del Renacimiento del siglo XII.

3 En concreto, vol. II, pp. 244-248.

4 «Petri Compostellani De consolatione rationis libri duo. E codice Biblioth. Reg. Monast. Escorialensis primun edidit prolegomenisque instruxit, P. Petrus Blanco Soto, O.E.S.A.», Beiträge zur Geschischte der Philosophie der Mittelalters, Band VIII, Heft 4, 151 pp., Münster i. W., 1912 (Aschendorffsche Verlagsbuchhandlung).

5 Publicado en Cuadernos de Estudios Gallegos, tomo XXIX, fascículos 87-88-89, año 1974-1975, (Santiago de Compostela), pp. 65-101.

6 Publicado por Verlag der Bayerischen Academie der Wissenschaften, Múnich, 1975, 108 pp. (Incluye al final una edición facsímil del manuscrito del Escorial en el que se contiene la obra). 
investigación hay que subrayar el enorme esfuerzo por tratar de comprobar en las principales bibliotecas del mundo si se encontraba otro ejemplar de la obra. La respuesta es tajantemente negativa. Es curiosa también su hipótesis sobre las pistas que pueden llevar a la identificación del autor del escrito.

\section{Fecha de composición}

Desde los primeros estudiosos hasta hoy la datación se mueve entre dos opiniones, una que le asigna el siglo XII. Fue la opinión mayoritaria durante muchos años. La otra le asigna el siglo XIV. Sin poder entrar en detalles sostenemos que ésta es la opinión más fundada.

El razonamiento reducido a lo esencial: la Obra está dedicada al Arzobispo Compostelano Berengarius (Berenguel). Hubo dos arzobispos con este nombre en Santiago, uno del siglo XII, otro del XIV. Hay datos que ponen de manifiesto que no puede referirse al Berengarius del XII:

1.9) La influencia de Alano de Lille, que muere a principios del siglo XIII.

2. -) Se cita la celebración en Santiago de la fiesta litúrgica de Santo Domingo, por supuesto posterior al siglo XII.

3.9) Se ve por la obra que el autor conoce el nuevo Aristóteles, hecho que, como es sabido, no sucede en Occidente hasta bien entrado el siglo XIII.

Por tanto, el Berengarius que se cita es el que presidió la Diócesis Compostelana en el siglo XIV, de origen francés. La Obra, pues, De Consolatione Rationis fue compuesta en el siglo XIV.

\section{El autor}

En lo que se refiere a la identificación del autor del escrito en cuestión, las dificultades se agrandan cuanto más pretendemos aproximarnos al tema. Es un problema totalmente abierto, y cuya solución tal vez nunca será posible de un modo apodíctico. Tan sólo quisiera dejar constancia de algunos datos significativos. Ante todo, damos por sentado que el autor pertenece al siglo XIV, y ahí hay que rastrearlo, no en el siglo XII como se ha pretendido en otros momentos. Hasta ahora se dio siempre por supuesto que Pedro Compostelano era un escritor de Santiago de Compostela, por el conocimiento que muestra de la urbe milenaria y de su comarca. No obstante, hay alguna hipótesis que plantea la posibilidad de que nuestro autor escribiese la obra fuera de tales lares. ${ }^{7}$

\section{ANÁLISIS DE LA DIMENSIÓN ÉTICA DE LA OBRA DEL COMPOSTELANO}

Ya queda dicho al inicio que nuestro objetivo es mostrar la dimensión ética de la Consolación de la Razón. Prescindo por ello de otra serie de aspectos de tipo teológico,

7 Remito para el tema a las sugerencias de María González-Haba en su trabajo citado. 
científico y literario que son relevantes, dado el carácter enciclopédico de la obra. Trataremos de hacer la presentación del tema aportando bastantes pasajes del propio autor, dada la enorme dificultad del contacto directo con el escrito del Compostelano. ${ }^{8}$

Comienza el escrito con una extensa dedicatoria en verso al Arzobispo Compostelano, que constituye el Proemio:

«Prelado Compostelano, Berenguel (Berengari) que buscas lo honesto y repruebas [lo malo.

Noble eres, bien distingues, eres probo, tienes

Fama de integridad; la sombra de los vicios lejos de ti está.

De lo recto amigo, talante moderado, incapaz de lo indecente;

Según lo preceptuado encaminas tu mente al Rey del cielo.

A la Iglesia propia custodiando,

Te has manifestado excelente regidor, impidiendo la presencia de cualquier traición. Maestro en la doctrina ajustada a la ley divina.

Buscas a los probos, rechazas a los réprobos, ministro de Cristo

Ya te muestras, ante nadie claudicas,

Alcanzas la más alta rectitud [...]

$\mathrm{Y}$ no por eso te veo ansioso de alabanzas, aunque sean lícitas. Perdonas al reo, consuelas al afligido,

Al cual la razón honesta permite consolar,

Al mismo tiempo ensalzas las buenas conductas [...]

Mereces estar al lado de Dios, Rey del cielo9.»

Después de este elogioso Proemio, según nos adentramos en el Primer Libro (de los dos que constituyen la obra) van apareciendo y participando en el diálogo una serie de personajes que le dan un carácter muy escénico a la exposición. El problema de fondo que plantea nuestro autor es el de una persona humana (en concreto un joven) que se encuentra ante la vida con enigmas e inquietudes sin tener claro cuál ha de ser el camino que debe seguir y la meta por conquistar. En una palabra, titubea. El autor tratará de responder al problema de fondo con clarividencia, buscando la orientación adecuada. Pretende que entremos en escena, pues se trata de una incógnita universal, insoslayable y, por ello, apasionante.

Los principales personajes, además, del propio Compostelano, son el Mundo, la Carne y la Razón; todos ellos representados por bellísimas doncellas. En torno a estos protagonistas irán agrupándose otra serie de personajes, dando un carácter dramático y vital al discurso.

En el Libro Segundo el aparato escénico se reduce al mínimo y se van planteando temas teológicos muy discutidos en los siglos medievales: el problema del mal y su origen, la conciliación de la libertad humana y la presciencia divina, el pecado original y su

8 Remitiré a las páginas de la transcripción latina del $P$. Blanco Soto (en adelante: $B S$ ), y a la paginación del Códice Escurialense (en adelante: CE; a la paginación del Códice le seguirán las letras « $\mathrm{r} »=$ recto, « $v »=$ vuelto). La versión al castellano es obra del que suscribe este trabajo.

9 BS, p. 52. CE, f. 33v. 
trasmisión, temas de Teología Mariana, sobre todo, la Concepción Inmaculada, etc. Prescindo de toda esta temática y me limitaré exclusivamente al primer libro, en consonancia con el objetivo inicial.

La alternativa que se plantea es entre el vicio y la virtud (bien y mal). Esta zozobra se refleja en las siguientes palabras:

«Pues ya vacilante inquiero con qué artes piensas que puedo curarme, y si crees que para mí hay remedio». ${ }^{10}$

Se presentan distintas soluciones y propuestas, unas positivas, otras negativas. En primer lugar, acude en auxilio del joven vacilante el Mundo:

«Esta doncella, pues, bellísima, con atavíos de varios colores, ceñida con diversas flores primaverales y mostrando la imagen del mundo comenzó a hablar». ${ }^{11}$

Le ofrece su solución para la vida: un camino lleno de rosas y placeres (vino, sexo, riquezas), y promete curar su mal. En toda la descripción del mundo el autor hace gala de un talante literario, artístico, poético. Lo presenta como verdaderamente fascinante y, ante la resistencia en aceptar la solución mundana, recalca el Mundo:

«La dureza de tu corazón permite ver el comienzo de tu futura perdición[...] Hay que desesperar de la curación de aquel cuyos oídos permanecen sordos, de tal modo que hasta rechaza el oír hablar de la salud».12

Por si fuera poco convincente el discurso del Mundo, otra bella y joven amiga suya lo apoya con sus dotes persuasorias: la Carne (Caro). Emplea un lenguaje directo y sencillo:

«¿Por qué rechazas las cosas terrenas tan llenas de bienes?... Mis placeres se veneran en todas partes[...]. Busca[...] los abundantes goces que el mundo tan fecundo ofrece; estas cosas las ves aunque la fe te hable de cosas futuras».13

Insiste la Carne en una especie de agnosticismo metafísico al señalar que la mente no puede volar sobre los astros. Estando el joven, Compostelano, en plena duda e inquietud ante la fascinación de la Carne y su colega el Mundo, hace aparición el protagonista central: la Razón (Ratio), también encarnada en forma de «doncella resplandeciente con inmensa claridad de rostro más humilde y mostrando el rubor del pudor original». De un modo airado le increpa:

10 BS, p. 54. CE, f. 34 r.

11 Loc. cit.

12 BS, p. 55. CE, f. 34v.

13 BS, p. 56. CE, f. 34v. 
"¿Por qué aquí a éste le asedian las meretrices de cieno, aduladoras, embusteras, seductoras de corazones inexpertos, que con apariencia de hostil amistad (sub hostili amicitia), como sirenas entonando melodía conducen al exterminio mortal?»

E inmediatamente prosigue el autor:

«¿Por qué dejas que peligren los dones que recibiste? Es asombroso que tú, alimentado por el grupo de mis doncellas, te dejes llevar de modo miserable al abismo de la sensualidad. Entonces, dejando a un lado el torpe deseo del ilusorio placer, apareció delante de mí el ejército de las doncellas vírgenes, con las cuales en otro tiempo aliviaba mis tristezas». ${ }^{14}$

Observamos cómo la Razón también tiene su equipo de doncellas que la defienden y protegen. Habla del placer sensible como algo ilusorio y de la inclinación al mismo como «torpe deseo» ${ }^{15}$. Inmediatamente se concreta cuál es el grupo de las buenas doncellas que con la Razón forman el antídoto del grupo anteriormente citado: en primer lugar las Artes Liberales (Trivio y Cuadrivio). Reseña con breves pinceladas cada una: la Gramática, la primera disciplina, algo así «como la leche materna...» La Lógica (no utiliza el término «dialéctica») es la segunda disciplina, «penetra en el interior de la mente [...], prepara para la lucha [...]. Nos enseña a razonar correctamente y a desvelar las falacias». La Retórica: «disciplina del buen decir y del arte de persuadir...» Después de escuchar a estas doncellas del equipo de la Razón, «reconocí que por las riquezas de éstas había sido deleitado en la flor de mi juventud primera». ${ }^{16}$ Hace una bonita alusión a la importancia de los escritos (que nos recuerda lo que Juan de Salisbury afirma en el Policraticus): «toda gloria mortal es efímera aunque tan diligentemente se busca perpetuar el recuerdo de los hechos humanos en los escritos». ${ }^{17}$

Ahora de modo expreso defiende la dimensión trascendente del hombre (lo cual ya estaba implícito anteriormente). No somos para la tierra, somos meros viatores hacia el Cielo. Es nuestra auténtica patria y meta definitiva. «Hemos de mirar las cosas celestiales [...], abrazarás vida más feliz si adviertes que sólo el rostro humano se muestra levantado hacia el Cielo». ${ }^{18} \mathrm{La}$ felicidad en esta vida es totalmente imposible. Hay como una espada que pende sobre nosotros constantemente: la muerte, «siempre nos amenaza inminente» y hace imposible la felicidad en esta vida.

14 BS, pp. 60-61. CE, f. 36r. Son obvias en este pasaje las resonancias de afirmaciones de Boecio en el De Consolatione Philosophiae.

15 Sin duda están latentes en la mente de nuestro autor resonancias epicúreas y estoicas.

16 BS, p. 63. CE, f. 36v.

17 BS, p. 64. CE, f. 36v.

18 Loc. cit. 
«La felicidad en este mundo es [...] enajenación de la mente, es debilidad de la razón, que así te hace perder el buen sentido y empuja el ánimo a la pasión, de modo que debes evitar las cosas transitorias y caducas que se presentan con cierta persuasión abominable de las meretrices en forma de vínculo de amor, y así generalmente nos vemos sorprendidos por el peligro». ${ }^{19}$.

El grupo de las doncellas benefactoras se amplía con el Cuadrivio (Aritmética, Geometría, Música y Astrología). Y se refuerza, ya en la dimensión trascendente del hombre, con las virtudes cardinales y teologales. Entre éstas la más sublime es la Caridad. La Razón en un bello cántico termina con estas palabras:

«Lejos de estas miserias disfrutarás elevándote hasta cerca del Cielo, si pones tu voluntad en servir al Dios celestial. Si al mundo como inmundo lo desprecias en toda ocasión. Entonces unido con las realidades superiores podrás ser puesto sobre las cosas arduas».20

Después de un prolongado silencio, Compostelano contesta a la Razón:

«Tus doncellas superan en belleza y distinción a las terrenas, pero es demasiada insensatez pedir que me aparte de aquéllas totalmente, pues no existe pecho tan duro que no se ablande con sus halagos. Ciertamente se ha de renunciar a éstas en cuanto es posible a la naturaleza, pero la naturaleza exige el uso del cuerpo, por eso es templanza usar de ellas en cuanto son artículo de necesidad». ${ }^{21}$

La Razón reprocha a Compostelano este intento de flirteo o concesión hacia las doncellas perversas:

« OOh joven! ¿Por qué estás preso en las cosas de la carne?[...] ¿Sabes que morirás? Y carecerás de los bienes superiores si siguieses las palabras de las bellas doncellas en lo íntimo de tu corazón».22

Insiste la Carne, tratando de ganar a Compostelano, y se entabla un fuerte altercado entre aquélla y la Razón. La Carne amenaza con un nuevo ejército capitaneado por la Lujuria, la Intemperancia, la Avaricia, la Gula. La Razón contesta que ya por su aspecto estas doncellas no pueden competir con las suyas. Después de un prolongado altercado, la Carne derrotada acaba rindiéndose a la Razón, y embargada por un curioso y profundo llanto acepta sus enseñanzas. He aquí los versos que constituyen el Planctus de la Carne:

19 BS, p. 65. CE, f. 37r.

20 BS, p. 72. CE, f. 38v.

21 BS, pp. 74-75. CE, f. 39v.

22 BS, p. 75. CE, f. 39v. 
«Pobreza, dolor, hambre, lamentaciones, ruina,

Debilidad, fatiga, inconstancia, tribulación, rapiña, Engaño, terror, llanto, error, disensión, pena, Lujo, amor de la muerte, grito de odio, azote, Vigilancias nocturnas, insidias, dispendios, preocupaciones, Astucia, dolo, impiedad, duros ayunos, Litigio, usura, hambre, aflicción, vida sofística, Muerte, lágrimas, terror del alma, amor fingido, Ira corrosiva, graves peligros, voluntad maligna, Exhausta vejez, maldito bajo el aura del placer, Muerte, gemido, temor escondido, fortuna doble, Falsa alianza, amor funesto, suerte entrelazada con penas, Engaño del mundo lleno de enfermedad, sin don duradero, Conflicto, odio, podredumbre, vicio, criminal pasión, Ambición, maligna condición, falacia inútil, Desenfreno mundano, carne efímera ahuyentadora de la serenidad, Codicia de riquezas, gemido de los miserables, terror de los vicios, Sosiego frágil, día pesado, miedo de los trabajos, Tormenta, calor estival y tempestad desatada, Rocío, lluvia, aguas que todo lo cubren, nieve cándida Frío y calor, torpe profesión, de la lujuria Venus viva, llena de vicios, chupadora incansable. ¿Y qué más? Grave preocupación, grave dolor me oprime, $Y$ a la pobre joven viciosa sacude la contrición.

Las cosas del mundo son causa de perdición para los viciosos, $Y$ grave turbación son para los religiosos.

La musa a Marón, las doctrinas a Platón, las alabanzas a Salomón No redimieron, y la perfidia no libró de la muerte a Nerón. ¿Por qué pues análogamente voy siguiendo yo lo perecedero? Diariamente bebo la muerte como un licor, Ya con la muerte la peste fuerte arrebata a los humanos.

Como queriendo con los vicios propios condenarse eternamente, renunciado a la salvación, se conducen Los que siguen los preceptos inmundos de este mundo». ${ }^{23}$

El joven, Compostelano, confiesa:

«Perdona, te ruego. Me avergüenzo de la ceguera; por la razón ciertamente me veo obligado a confesar no haber ningún defecto por parte de Dios, pero nosotros al apartarnos de Él llegamos a ser miseria». ${ }^{24}$ 
Alude nuestro autor a un tema que todavía no había explicitado: para seguir el programa de la Razón no bastan las fuerzas humanas, hace falta el don que los teólogos llaman Gracia:

«¿Quién podrá, faltándole tu gracia, ser conducido a los poderes superiores? 0 ¿quién por éstos será llevado sobre los astros? Todo bien es un don del Omnipotente [...] por el cual es dirigida la prudencia del ánimo [...] por el cual se elimina el propio vicio mediante el lavado». ${ }^{25}$

La Ratio de que habla el autor del De Consolatione Rationis es una Ratio Theologica. Se pasa de lo meramente racional (en nuestra terminología) a la creencia $(\mathrm{Fe})$ con una naturalidad asombrosa para la mentalidad actual, pero no en vano la época medieval se caracteriza no sólo por ser teocéntrica en su cultura, sino también por ser teológica en su racionalidad. La narración del Primer Libro termina con unos sentidos versos que describen la «Conversión de la Carne» y al mismo tiempo ponen de manifiesto la notoria dimensión ética de la obra:

«Si experimentas verdadera contrición,

He aquí que en pocas palabras te descubro el camino de la salvación:

Huye la pereza, la gloria del reino celeste

No se dará al perezoso y no abre caminos a los astros, pero sobre el cielo, hay para ti magna corona,

Si inclinas la cabeza para rendir culto a Dios.

Si para ti lo que antes te llevó a la miseria

Abandonas, purgándote con la ofrenda del corazón contrito,

No te sometas a la carne, y no sea el vientre tu preocupación.

Sigue a la naturaleza para que no padezcas vicio.

Éste pide demasiado, aquélla con poco descansa satisfecha,

Él no sabe de moderación; así corre a la corrupción.

Perdona al impetuoso, que vuelve a la medida justa,

$Y$ no te consumas con la sumisión al vino,

Que oscurece la verdad y origina vicio.

Contén la lengua, mirando al rey dirige tus pasos,

Y gradúa tu andar para que no aparezcas apresurado.

Mala lengua lleva veneno, quema más que el fuego,

Más que la espada daña, más que el guerrero hiere.

Domina tus oídos, para no oír palabras malignas

$O$ indignas o cosa que en tu daño se vuelva,

Pues si algún reprobado vicio percibe tu oído

$O$ te dañarás o provocarás odio.

Contén tus ojos porque son sendas de vicio,

Son huéspedes de las costumbres, son hoyos,

25 BS, p. 75. CE, f. 39v. 
$\mathrm{Y}$ el que guarda bien sus ojos bien se guarda, $\mathrm{Al}$ evitar que actúe el estímulo.

El contacto de las manos o el abrazo de las mujeres, A decir verdad, se convierte en vicio;

De modo que si no evitas incluso pensar en la mujer, Apenas estarás inmune. Para que carezcas de vicio

No estimules el gusto con especias, o el aroma de los brebajes soporíferos, Pues es vil el hombre que con estas cosas se complace,

Ya que las comidas condimentadas con pimienta dan energías venéreas, $Y$ enturbian el cuerpo de modo que se produce la falta.

Huye de la pereza, vigila, medita, trabaja,

Reza con insistencia para que no padezcas vicios.

Pues el trabajo extenúa y evita que el maligno domine con sus tentaciones. Ejercita los miembros, huye el crimen del rocío, porque a los superiores Rindas culto en lo interior, a la vez que exteriormente.

Pronto perecen las cosas que parecen deleitar,

$Y$ cuando se pierden no vuelven otra vez.

Si obras rectamente, esto no lo podrá destruir el tiempo,

Esto no se marchitará, sino que abre caminos hacia los astros.

Evita toda maldad, para que vivas aquí y en la eternidad, Y no sufras muerte, pero merezcas así,

Con la mente toda vuelta a Dios, a Él saltar. Lo que en la boca se mueva Dentro se vierta en nota íntima.

Sea tu voz suave, tu aspecto digno, tus acciones honestas,

Tus ademanes elegantes, tu mente piadosa y humilde». ${ }^{26}$ 